\title{
Sistem Pemantauan Kondisi Air Hidroponik Berbasis Internet of Things Menggunakan NodeMCU ESP8266
}

\section{Monitoring System of Hydroponic Water Condition Based on Internet of Things by Node MCU ESP8266}

\author{
Ahmad Izzinnahdi ${ }^{1}$, Randi Adzin Murdiantoro ${ }^{2, *}$, Edmund Ucok Armin $^{3}$ \\ 1,2,3 Program Studi Teknik Elektro, Universitas Peradaban Bumiayu \\ Jl. Raya Pagojengan, Km. 3, Paguyangan, Brebes, Jawa Tengah, Brebes \\ 2,*Penulis korespondensi: randi.adzin.m@gmail.com \\ 1.izziqwerty@gmail.com, ${ }^{3}$ edmundarmin@gmail.com
}

Received on 10-06-2021, accepted on 03-08-2021, published on 17-09-2021

\begin{abstract}
Abstrak
Salah satu bentuk kemajuan di bidang teknologi informasi adalah platform Internet of Things (IoT). Salah satu aspek yang dapat menerapkan konsep ini adalah aspek industri pertanian. Para petani biasanya menggunakan tanah sebagai media tanam, tetapi dalam kemajuan infrastruktur di Indonesia membuat lahan pertanian kian berkurang. Akan tetapi kebutuhan akan pangan harus tetap terpenuhi. Hidroponik adalah salah satu metode budidaya tanaman menggunakan air dan larutan nutrisi sebagai media tanam. Kondisi air dalam hidroponik sangat penting untuk di periksa secara berkala karena berpengaruh terhadap serapan hara dan ketersedian nutrisi, hal tersebut dipengaruhi oleh kondisi pH larutan, konduktivitas listrik, komposisi nutrisi dan suhu. Untuk menghasilkan keputusan yang tepat petani membutuhkan data realtime tentang kondisi air. Pada penelitian ini NodeMCU ESP8266 diimplementasikan sebagai mikrokontroller pada sistem pemantauan kondisi air hidroponik berbasis IoT. Sensor yang digunakan antara lain Sensor Ultrasonik HC-SR04, Sensor Suhu DS18B20, dan Sensor pH E-201C. Data hasil baca dari seluruh sensor dapat di lihat secara realtime di dalam sebuah website yang dapat diakses melalui smartphone.
\end{abstract}

Kata Kunci: NodeMCU ESP8266, Ultrasonik, pH E-201C, Internet of Things, Hidroponik.

Abstract

The Internet of Things (IoT) platform is a form of advancement in the field of Information Technology applied in the farming industry. Farmers often use soil to grow crops. Though the soil is essential for farming, the use for agriculture steadily reduced because of Indonesia's infrastructure advancement. However, the country's have to fulfill their food needs. Hydroponics is a method of growing crops using water and nutritious solutions as a growing media. In this method, monitoring water conditions from time to time is a must to ensure the crops absorb enough nutrients. The water parameters are $\mathrm{pH}$, electrical conductivity, temperature, and nutritions composition. The real-time values of those parameters are important to decide the treatment of the crop. In this experiment, NodeMCU ESP8266, a microcontroller, was implemented as a monitoring system based on loT. The sensors for this system are Ultrasonic HCSR04, DS18B20 temperature sensor, and E-201C pH sensor. The results of all sensors can be accessed in real-time on a website by smartphone.

Keywords: NodeMCU ESP8266, Ultrasonic, pH E-201C, Internet of Things, Hydroponic. 


\section{Pendahuluan}

Pekembangan teknologi informasi semakin pesat dari waktu ke waktu, teknologi informasi dapat dirasakan langsung oleh manusia dan mengalami perubahan yang signifikan di beberapa sektor kehidupan. Salah satu bentuk kemajuan di bidang teknologi informasi adalah platform Internet of Things (IoT). Internet of Things (IoT) iadalah istilah yang sedang ramai dibicarakan di kalangan milenial saat ini. Konsep IoT memungkinkan semua benda dapat berkomunikasi satu sama lain melalui Internet, $I o T$ mengacu pada penggunaan perangkat dan sistem cerdas yang terhubung untuk memanfaatkan data yang dikumpulkan oleh sensor dan aktuator yang tertanam di mesin dan benda fisik lainnya [1]. Konsep ini bisa di gunakan di berbagai aspek kehidupan di era modern. Salah satu aspek yang dapat menerapkan konsep ini adalah aspek industri pertanian.

Pertanian merupakan sektor yang sangat penting bagi masyarakat Indonesia. Para petani biasanya menggunakan tanah sebagai media tanam, tetapi dalam kemajuan infrastruktur di Indonesia membuat lahan pertanian kian berkurang. Akan tetapi kebutuhan akan pangan harus tetap terpenuhi, sehingga petani harus menggunakan cara lain untuk bercocok tanam tanpa harus menggunakan media tanam yang luas.

Hidroponik adalah salah satu metode di industri pertanian yang dapat membudidayakan tanaman tanpa memerlukan lahan tanah, tetapi menggunakan air dan larutan nutrisi sebagai media tanam. Budidaya hidroponik ini memiliki banyak keuntungan diantaranya perawatan lebih praktis serta gangguan hama lebih terkontrol, tidak bergantung pada kondisi alam, dan dapat dilakukan pada lahan yang terbatas [2].

Kebutuhan pangan bagi manusia seperti sayuran dan buah-buahan semakin meningkat dengan seiring perkembangan jumlah penduduk, oleh sebab itu banyak perusahaan yang bergerak di bidang holticultura sebagai penyuplai kebutuhan pangan di Indonesia. Budidaya hidroponik untuk keperluan dalam skala besar (balai penelitian, produksi penjualan) sangat penting memperhatikan kualitas dan kondisi air, supaya tanaman dapat bertumbuh kembang dengan baik, air perlu di periksa secara berkala agar mendapatkan hasil tanaman yang optimal.

Sesuai dengan namanya hidroponik berarti sistem penanaman dengan media air, maka kondisi air sangat penting untuk di periksa secara berkala karena berpengaruh terhadap serapan hara dan ketersedian nutrisi, hal tersebut dipengaruhi oleh kondisi pH larutan, konduktivitas listrik, komposisi nutrisi dan suhu [3]. Kualitas dan kondisi air yang harus diperhatikan dalam penelitian ini adalah distribusi air, $\mathrm{pH}$, suhu, dan kebutuhan listrik untuk sirkulasi air.

Optimasi produk pertanian dipengaruhi situasi-situasi tertentu seperti perkiraan cuaca, keadaan tanah, dan kebutuhan pasar terhadap tanaman tertentu. Untuk menghasilkan keputusan yang tepat petani membutuhkan data realtime tentang kondisi air saat itu. Untuk menghasilkan keputusan yang tepat petani membutuhkan data realtime tentang kondisi air saat itu lalu secara efisien bisa mengelola penggunaan energi yang digunakan. Semuanya secara real-time [4].

Pada penelitian ini NodeMCU ESP8266 diimplementasikan sebagai sebagai mikrokontroller pada sistem pemantauan kondisi air hidroponik berbasis IoT. NodeMCU ESP8266 merupakan modul turunan pengembangan dari modul platform IoT keluarga ESP8266 tipe ESP-12 [5]. Agar dapat digunakan ESP8266 diperlukan beberapa teknik wiring serta tambahan modul USB to serial untuk mengunduh program. Namun NodeMCU ESP508266 telah mengkompakkan ESP8266 ke dalam sebuah papan yang kompak dengan berbagai fitur layaknya mikrokontroler dengan kapabilitas akses terhadap Wifi juga chip komunikasi USB to serial. Sehingga untuk memprogramnya hanya diperlukan ekstensi kabel data USB yang digunakan untuk charging smart phone [6]. Secara fungsi modul ini hampir menyerupai dengan platform modul arduino, tetapi yang membedakan yaitu dikhususkan untuk Connected to Internet [5].

\section{KaJian Pustaka}

\section{A. Internet Of Thing}

Internet of Thing adalah istilah yang sedang ramai dibicarakan dikalangan milenial saat ini, Internet of Thing atau dikenal juga dengan singkatan IoT, merupakan sebuah konsep yang bertujuan untuk memperluas manfaat dari konektivitas Internet yang tersambung secara terus-menerus yang memungkinkan kita untuk menghubungkan mesin, peralatan, dan benda fisik lainnya dengan sensor jaringan dan aktuator untuk memperoleh data dan mengelola kinerjanya sendiri, sehingga memungkinkan mesin untuk berkolaborasi dan bahkan bertindak berdasarkan informasi baru yang diperoleh secara independen. Pada dasarnya perangkat IoT 
terdiri dari sensor sebagai media pengumpul data, sambungan internet sebagai media komunikasi dan server sebagai pengumpul informasi yang diterima sensor dan untuk analisa [10].

\section{B. Hidroponik}

Hidroponik adalah lahan budidaya pertanian tanpa menggunakan media tanah, sehingga hidroponik merupakan aktivitas pertanian yang dijalankan dengan menggunakan air sebagai medium untuk menggantikan tanah. Sehingga sistem bercocok tanam secara hidroponik dapat memanfaatkan lahan yang sempit [2].

Kondisi air sangat penting untuk di periksa secara berkala karena berpengaruh terhadap serapan hara dan ketersedian nutrisi, hal tersebut dipengaruhi oleh kondisi $\mathrm{pH}$ larutan, konduktivitas listrik, komposisi nutrisi dan suhu [3]. Kualitas dan kondisi air yang harus diperhatikan dalam penelitian ini adalah distribusi air, $\mathrm{pH}$, suhu, dan kebutuhan listrik untuk sirkulasi air. Pada hidroponik pH merupakan faktor yang penting untuk dipantau. Formula nutrisi yang berbeda mempunyai $\mathrm{pH}$ yang berbeda, karena garam-garam pupuk mempunyai tingkat kemasaman yang berbeda jika dilarutkan dalam air. Garam garam seperti monokalium fosfat, tingkat kemasamannya lebih rendah daripada kalsium nitrat [12].

\section{NodeMCU ESP-8266}

NodeMCU ESP-8266 merupakan sebuah open source platform IoT dan pengembangan kit dari ESP8266 yang menggunakan bahasa pemrograman eLua untuk membantu pembuat dalam membuat produk IoT atau bisa dengan memakai sketch dengan arduino IDE. ESP8266 sendiri merupakan chip WiFi dengan protokol TCP/IP yang lengkap. NodeMCU ESP-8266 juga memiliki board yang berukuran sangat kecil yaitu panjang $4.83 \mathrm{~cm}$, lebar $2.54 \mathrm{~cm}$. NodeMCU ESP8266 menawarkan kemudahan untuk melakukan pengembangan perangkat berbasis Internet karena sudah dilengkapi modul komunikasi Wireless Firewall (WiFi). NodeMCU dapat dianalogikan sebagai board arduino-nya ESP8266. Program ESP8266 sedikit merepotkan karena diperlukan beberapa teknik wiring serta tambahan modul USB to serial untuk mengunduh program. Namun NodeMCU ESP-8266 telah menyatukan ESP8266 ke dalam sebuah board yang minimalis dengan berbagai fitur layaknya mikrokontroler yang mempunyai akses terhadap WiFi juga chip komunikasi USB to serial. Sehingga untuk memprogramnya hanya diperlukan kabel data USB [6].

\section{Sensor pH E-201C DF Robot Kit V2}

Sensor pH E-201C adalah sebuah alat elektronik yang digunakan untuk mengukur pH (derajat keasaman atau kebasaan) dari suatu cairan. Sistem kerja dari sensor terletak pada probe $\mathrm{pH}$ yang terbuat dari kaca. Reaksi kimia pada ujung probe $\mathrm{pH}$ menyebabkan tegangan dan dari tegangan tersebut diukur menjadi satuan $\mathrm{pH}$. Prinsip kerja dari pH yaitu semakin banyak elektron pada sampel makan akan semakin bernilai asam begitu pula sebaliknya, karena di dalam probe $\mathrm{pH}$ meter berisi elektrolit lemah [13].

Skema elektroda $\mathrm{pH}$ meter akan mengukur potensial listrik antara merkuri klorid $(\mathrm{HgCl})$ pada elektroda pembanding dan potassium chloride $(\mathrm{KCl})$ yang merupakan larutan di dalam gelas elektroda serta potensial antara larutan dan elektroda perak. Tetapi potensial antara sampel yang tidak diketahui dengan elektroda gelas dapat berubah sesuai sampelnya [14].

\section{E. Sensor Suhu DS18B20}

Banyak sensor suhu yang dipakai dalam implementasi sistem instrumentasi, salah satu contohnya adalah DS18B20. Sensor suhu DS18S20 ini telah memiliki keluaran digital meskipun bentuknya kecil (TO-92), sensor ini sangat menghemat pin mikrokontroler, karena 1 pin mikrokontroler dapat digunakan untuk berkomunikasi dengan beberapa perangkat lainnya[14].

Sensor suhu pada umumnya membutuhkan ADC dan beberapa pin port pada mikrokontroler, namun DS18B20 ini tidak membutuhkan ADC agar dapat berkomunikasi dengan mikrokontroler dan hanya membutuhkan 1 wire saja. Sensor suhu DS18B20 adalah sensor suhu yang memiliki keluaran digital. DS18B20 memiliki tingkat akurasi yang cukup tinggi, yaitu $0,5^{\circ} \mathrm{C}$ pada rentang suhu $-10^{\circ} \mathrm{C}$ sampai $+85^{\circ} \mathrm{C}$. sehingga banyak dipakai untuk aplikasi sistem monitoring suhu[15].

\section{F. Sensor Ultrasonik HC-SR04}


HC-SR04 adalah sensor ultrasonik siap pakai, satu alat yang berfungsi sebagai pengirim, penerima dan pengontrol gelombang ultrasonik. Modul sensor pengukur jarak dengan gelombang ultrasonik. Modul Sensor ini memancarkan seberkas sinyal ultrasonik berbentuk pulsa, kemudian jika ada objek di depan sensor maka penerima akan menerima pantulan sinyal ultrasonik yang terhalang objek tersebut. Penerima akan membaca lebar pulsa (dalam bentuk PWM) yang dipantulkan objek dan selisih waktu pemancaran [16].

\section{G. MySQL}

MySQL adalah peragkat lunak yang tergolong sebagai database Management System (DBMS). MySQL merupakan manajemen basisdata yang paling stabil digunakan sebagai media penyimpanan data. Perangkat lunak ini bermanfaat untuk mengolah data dengan cara yang sangat fleksibel dan cepat. Database atau dalam Bahasa Indonesia basis data terdiri atas $2 \mathrm{kata}$, yaitu basis dan data. Basis kurang lebih dapat diartikan sebagai markas atau gedung tempat bersarang atau berkumpul. Sedangkan data adalah representasi fakta berita nyata yang mewakili suatu objek. MySQL merupakan turunan dari Structured Query Language (SQL), SQL merupakan operasional basisdata yang dapat dikerjakan dengan mudah dan otomatis. MySQL bertugas mengatur dan mengelola data-data pada database [17].

\section{H. PHP}

PHP adalah bahasa pemrograman untuk dijalankan melalui halaman web, umumnya digunakan untuk mengolah informasi di internet. Sedangkan dalam pengertian lain PHP adalah singkatan dari Hypertext Preprocessor yaitu bahasa pemrograman webserver-side yang bersifat open source atau gratis. PHP merupakan script yang menyatu dengan HTML dan berbeda pada server [17].

\section{Metodologi Penelitian}

Proses pengumpulan data dengan metode wawancara dan observasi untuk melakukan pengamatan dan analisa terhadap proses budidaya tanaman hidoponik sehingga mendapatkan data dan informasi yang dibutuhkan oleh peneliti.

Perancangan alat dilakukan dengan proses penentuan desain box, desain rangkaian, dan komponen apa saja yang harus digunakan, setelah desain sudah sesuai yang diinginkan, langkah selanjutnya adalah perakitan, proses coding, serta pembuatan prototype hidroponik.

Untuk mengetahui kinerja alat yang dibuat dan pada proses ini dapat dilakukan pengambilan data. Dalam proses uji coba alat dilakukan pengukuran alat. Pada hal ini pengukuran alat sangat penting dilakukan untuk mengetahui berfungsi atau tidaknya alat tersebut dan untuk mengetahui apakah perakitan sudah sesuai atau tidaknya.

Analisi data dilakukan guna identifikasi masalah pada sistem yang sedang berjalan. Dengan demikian, diharapkan peneliti dapat menemukan permasalahan yang terjadi pada proses budidaya hidroponik sehingga peneliti dapat mencari solusi untuk permasalahan tersebut.

\section{Hasil dan Pembahasan}

Sensor yang digunakan dalam peneitian ini terdiri dari dua yaitu sensor ultrasonik, suhu, dan $\mathrm{pH}$. Untuk pengujian sensor ultrasonik akan di ukur pada beberapa interval dan akan dibandingkan dengan pengukuran manual (penggaris), pengujian sensor suhu akan di ukur dan dibandingkan dengan pengukuran manual (termometer mercuri), dan pengujian sensor $\mathrm{pH}$ dibandingkan dengan $\mathrm{pH}$ meter yang sudah terkalibrasi.

\section{A. Pengujian Sensor Ultrasonik}

Pada pengujian sensor ultrasonik dilakukan perbandingan antara hasil baca sensor HC-SR04 dengan penggaris. Dimaksudkan agar dapat diketahui selisih antara sensor ultrasonik dan penggaris. Hasil dari pengujian sensor ditampilkan pada serial monitor arduino IDE. Pengujian dilakukan dengan objek benda cair karena akan diaplikasikan pada benda cair, Berikut rangkuman hasil dari pengujian sensor dapat dilihat pada Tabel 1. 
Tabel 1 Pengujian Sensor Ultrasonik

\begin{tabular}{|c|c|c|c|}
\hline Pengujian Ke- & Sensor Ultrasonik & Penggaris & Selisih \\
\hline $\mathbf{1}$ & 3 & 0 & $\sim$ \\
\hline $\mathbf{2}$ & 2 & 2 & 0 \\
\hline $\mathbf{3}$ & 5 & 5 & 0 \\
\hline $\mathbf{4}$ & 10,52 & 10 & 0,52 \\
\hline $\mathbf{5}$ & 14,80 & 15 & $-0,20$ \\
\hline $\mathbf{6}$ & 19,75 & 20 & $-0,25$ \\
\hline $\mathbf{7}$ & 29,76 & 30 & $-0,24$ \\
\hline $\mathbf{8}$ & 39,75 & 40 & $-0,25$ \\
\hline $\mathbf{9}$ & 58,9 & 60 & $-1,1$ \\
\hline
\end{tabular}

Hasil pengujian sensor ultrasonik dengan objek cair dengan batas minimal pengukuran yaitu dengan jarak 2 $\mathrm{cm}$ dan semakin jauh jarak sensor dengan objek, tingkat selisih makin tinggi (Gambar 1). Mapping yang dilakukan adalah dengan mengukur tinggi tandon air senilai $21 \mathrm{~cm}$ dan asumsi tinggi air $100 \%$ senilai $18 \mathrm{~cm}$ dengan persamaan (1) sebagai berikut :

$$
\text { Level Air }=100 \% \times \frac{18-\operatorname{Jarak}}{18}
$$

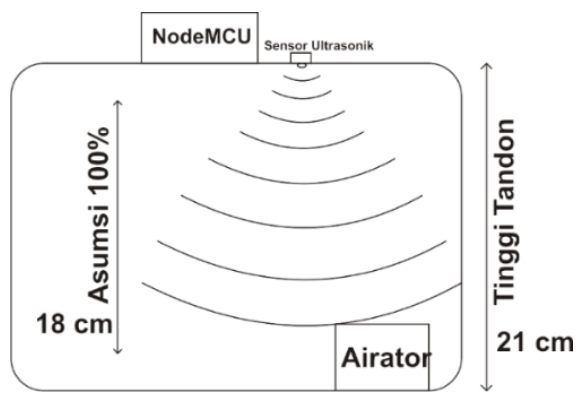

Gambar 1 Simulasi Mapping Sensor Ultrasonik

\section{B. Pengujian Sensor Suhu}

Pada pengujian sensor suhu dilakukan perbandingan antara hasil baca sensor DS18B20 dengan termometer merkuri (Gambar 2 (a)). Dimaksudkan agar dapat diketahui selisih antara sensor suhu dan termometer. Hasil dari pengujian sensor ditampilkan pada serial monitor arduino IDE dan interface website yang telah dibangun. Berikut rangkuman hasil dari pengujian sensor dapat dilihat pada Gambar 2 (b).

Dilihat dari hasil pengujian dapat disimpulakan bahwa hasil pembacaan antara sensor suhu DS18B20 dan termoter merkuri memiliki selisih yang tidak terlalu signifikan dikarenakan pembacaan sensor suhu mempunyai waktu respon \pm 1 menit untuk mendapatkan hasil yang sesuai. Berikut hasil dokumentasi pengujian sensor suhu DS18B20 dan termometer merkuri. 


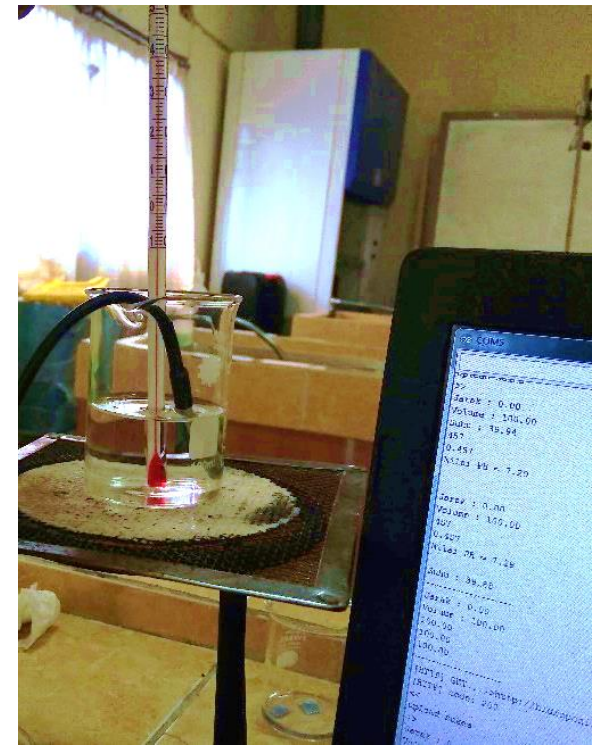

(a)

\begin{tabular}{c|c|c|c|c|}
$\begin{array}{c}\text { Sensor } \\
\text { DS18B20 }\end{array}$ & $\begin{array}{c}\text { Termometer } \\
\text { Merkuri }\end{array}$ & Selisih & Jam & Tanggal \\
\hline $40.56^{\circ} \mathrm{C}$ & $40.00^{\circ} \mathrm{C}$ & 0.56 & $01: 58: 01$ & $06-08-2020$ \\
\hline $40.50^{\circ} \mathrm{C}$ & $40.00^{\circ} \mathrm{C}$ & 0.50 & $01: 58: 07$ & $06-08-2020$ \\
\hline $40.44^{\circ} \mathrm{C}$ & $40.00^{\circ} \mathrm{C}$ & 0.44 & $01: 58: 13$ & $06-08-2020$ \\
\hline $40.44^{\circ} \mathrm{C}$ & $40.00^{\circ} \mathrm{C}$ & 0.44 & $01: 58: 19$ & $06-08-2020$ \\
\hline $40.38^{\circ} \mathrm{C}$ & $40.00^{\circ} \mathrm{C}$ & 0.38 & $01: 58: 25$ & $06-08-2020$ \\
\hline $40.31^{\circ} \mathrm{C}$ & $40.00^{\circ} \mathrm{C}$ & 0.31 & $01: 58: 31$ & $06-08-2020$ \\
\hline $40.31^{\circ} \mathrm{C}$ & $40.00^{\circ} \mathrm{C}$ & 0.31 & $01: 58: 37$ & $06-08-2020$ \\
\hline $40.31^{\circ} \mathrm{C}$ & $40.00^{\circ} \mathrm{C}$ & 0.31 & $01: 58: 43$ & $06-08-2020$ \\
\hline $40.25^{\circ} \mathrm{C}$ & $40.00^{\circ} \mathrm{C}$ & 0.25 & $01: 58: 49$ & $06-08-2020$ \\
\hline $40.06^{\circ} \mathrm{C}$ & $40.06^{\circ} \mathrm{C}$ & 0.06 & $01: 58: 54$ & $06-08-2020$ \\
\hline $40.06^{\circ} \mathrm{C}$ & $40.00^{\circ} \mathrm{C}$ & 0.06 & $01: 59: 00$ & $06-08-2020$ \\
\hline $39.94^{\circ} \mathrm{C}$ & $39.00^{\circ} \mathrm{C}$ & 0.94 & $01: 59: 06$ & $06-08-2020$ \\
\hline $39.88^{\circ} \mathrm{C}$ & $39.00^{\circ} \mathrm{C}$ & 0.88 & $01: 59: 12$ & $06-08-2020$ \\
\hline $39.88^{\circ} \mathrm{C}$ & $39.00^{\circ} \mathrm{C}$ & 0.88 & $01: 59: 18$ & $06-08-2020$ \\
\hline $39.81^{\circ} \mathrm{C}$ & $39.00^{\circ} \mathrm{C}$ & 0.81 & $01: 59: 27$ & $06-08-2020$ \\
\hline $39.81^{\circ} \mathrm{C}$ & $39.00^{\circ} \mathrm{C}$ & 0.81 & $01: 59: 33$ & $06-08-2020$ \\
\hline $39.69^{\circ} \mathrm{C}$ & $39.00^{\circ} \mathrm{C}$ & 0.69 & $01: 59: 39$ & $06-08-2020$ \\
\hline $39.63^{\circ} \mathrm{C}$ & $39.00^{\circ} \mathrm{C}$ & 0.63 & $01: 59: 44$ & $06-08-2020$ \\
\hline $39.56^{\circ} \mathrm{C}$ & $39.00^{\circ} \mathrm{C}$ & 0.56 & $01: 59: 50$ & $06-08-2020$ \\
\hline $39.44^{\circ} \mathrm{C}$ & $39.00^{\circ} \mathrm{C}$ & 0.44 & $01: 59: 56$ & $06-08-2020$ \\
\hline $39.38^{\circ} \mathrm{C}$ & $39.00^{\circ} \mathrm{C}$ & 0.38 & $02: 00: 03$ & $06-08-2020$ \\
\hline $39.31^{\circ} \mathrm{C}$ & $39.00^{\circ} \mathrm{C}$ & 0.31 & $02: 00: 08$ & $06-08-2020$ \\
\hline $39.25^{\circ} \mathrm{C}$ & $39.00^{\circ} \mathrm{C}$ & 0.25 & $02: 00: 14$ & $06-08-2020$ \\
\hline $39.13^{\circ} \mathrm{C}$ & $39.00^{\circ} \mathrm{C}$ & 0.13 & $02: 00: 20$ & $06-08-2020$ \\
\hline $39.06^{\circ} \mathrm{C}$ & $39.00^{\circ} \mathrm{C}$ & 0.06 & $02: 00: 27$ & $06-08-2020$ \\
\hline $39.00^{\circ} \mathrm{C}$ & $39.00^{\circ} \mathrm{C}$ & 0 & $02: 00: 32$ & $06-08-2020$ \\
\hline $38.94^{\circ} \mathrm{C}$ & $38.00^{\circ} \mathrm{C}$ & 0.94 & $02: 00: 38$ & $06-08-2020$ \\
\hline & & $(b)$ & & \\
\hline
\end{tabular}

(b)

Gambar 2: (a) Termometer Merkuri dan Sensor Suhu dan (b) Pengujian Sensor Suhu

\section{Pengujian Sensor pH}

Pada pengujian sensor $\mathrm{pH}$ dilakukan perbandingan antara hasil baca sensor $\mathrm{pH}$ E-201C dengan $\mathrm{pH}$ meter digital. Dimaksudkan agar dapat diketahui selisih antara sensor ultrasonik dan penggaris. Hasil dari pengujian sensor ditampilkan pada serial monitor arduino IDE. Pengujian dilakukan pada dua jenis larutan $\mathrm{pH}$ yang berbeda yaitu $\mathrm{pH} 4 \mathrm{pH}$ 7, Berikut rangkuman hasil dari pengujian sensor dapat dilihat pada Gambar 3 berikut:

\begin{tabular}{c|c|c|c}
$\begin{array}{c}\text { Pengujian } \\
\text { Ke- }\end{array}$ & $\begin{array}{c}\text { Sensor } \\
\mathrm{pH}\end{array}$ & $\begin{array}{c}\mathrm{pH} \\
\text { Meter }\end{array}$ & \multicolumn{1}{c}{ Selisih } \\
\hline 1 & 7.05 & 7.00 & 0.05 \\
\hline 2 & 7.05 & 7.00 & 0.05 \\
\hline 3 & 7.05 & 7.00 & 0.05 \\
\hline 4 & 7.03 & 7.00 & 0.03 \\
\hline 5 & 7.04 & 7.00 & 0.04 \\
\hline 6 & 7.03 & 7.00 & 0.03 \\
\hline 7 & 7.02 & 7.00 & 0.03 \\
\hline 8 & 7.01 & 7.00 & 0.01 \\
\hline 9 & 7.01 & 7.00 & 0.01 \\
\hline 10 & 7.01 & 7.00 & 0.01 \\
\hline
\end{tabular}

(a)

\begin{tabular}{|c|c|c|c|}
\hline $\begin{array}{c}\text { Pengujian } \\
\mathrm{Ke}-\end{array}$ & $\begin{array}{c}\text { Sensor } \\
\mathrm{pH}\end{array}$ & $\begin{array}{c}\mathrm{pH} \\
\text { Meter }\end{array}$ & Selisih \\
\hline 1 & 3.98 & 4.00 & -0.02 \\
\hline 2 & 4.00 & 4.00 & 0.00 \\
\hline 3 & 4.00 & 4.00 & 0.00 \\
\hline 4 & 4.02 & 4.00 & 0.02 \\
\hline 5 & 4.02 & 4.00 & 0.02 \\
\hline 6 & 4.04 & 4.00 & 0.04 \\
\hline 7 & 4.04 & 4.00 & 0.04 \\
\hline 8 & 4.02 & 4.00 & 0.02 \\
\hline 9 & 4.00 & 4.00 & 0.00 \\
\hline 10 & 3.98 & 4.00 & -0.02 \\
\hline
\end{tabular}

(b)

Gambar 3 Pengujian sensor pada: (a). larutan $\mathrm{pH} 7$ dan (b). larutan $\mathrm{pH} 4$

Setelah dilakukan pengujian pada $\mathrm{pH} 7$ dan $\mathrm{pH} 4$ yang di bandingkan antara pembacan dari sensor $\mathrm{pH}$ E-201 $\mathrm{C}$ dan ph meter digital terdapat selisih tidak terlalu siginifikan yaitu kisaran \pm 0.5 dan waktu respon pembacaan data dari sensor pH E $201 \mathrm{C}$ ini $\leq 1$ menit sesuai dengan spesifakasi dari sensor tersebut.

\section{Hasil Perancangan Alat}

Pada Gambar 5 (a) dan (b) adalah box yang berisi modul-modul sensor serta mikrokontroller yang sudah saling terintegrasi, box digunakan agar seluruh komponen sensor dan mikrokontroler dapat aman dari cipratan air. Pada Gambar 5 (c) adalah bagaimana tampilan ketika tandon dan box rangkaian dapat di terapakan pada prototype hidroponik. 


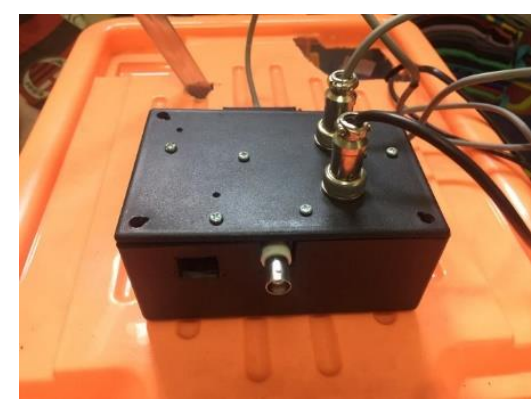

(a)

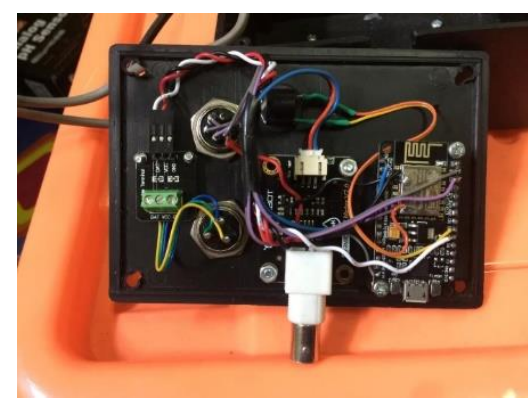

(b)

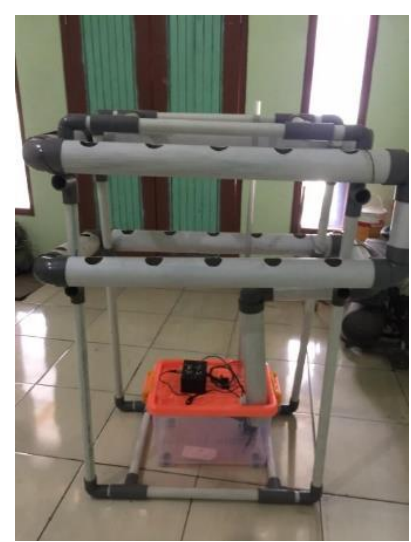

(c)

Gambar 5: (a) Box Pelindung Rangkaian, (b) Rangkaian, dan (c) Keseluruhan Prototype Hidroponik

Pada Gambar 6 adalah bentuk antarmuka dari website sistem monitoring, yaitu apat simpan sementara, dan terdapat tombol reset guna menghapus semua data logging jika ingin menghapus data logging sementara.

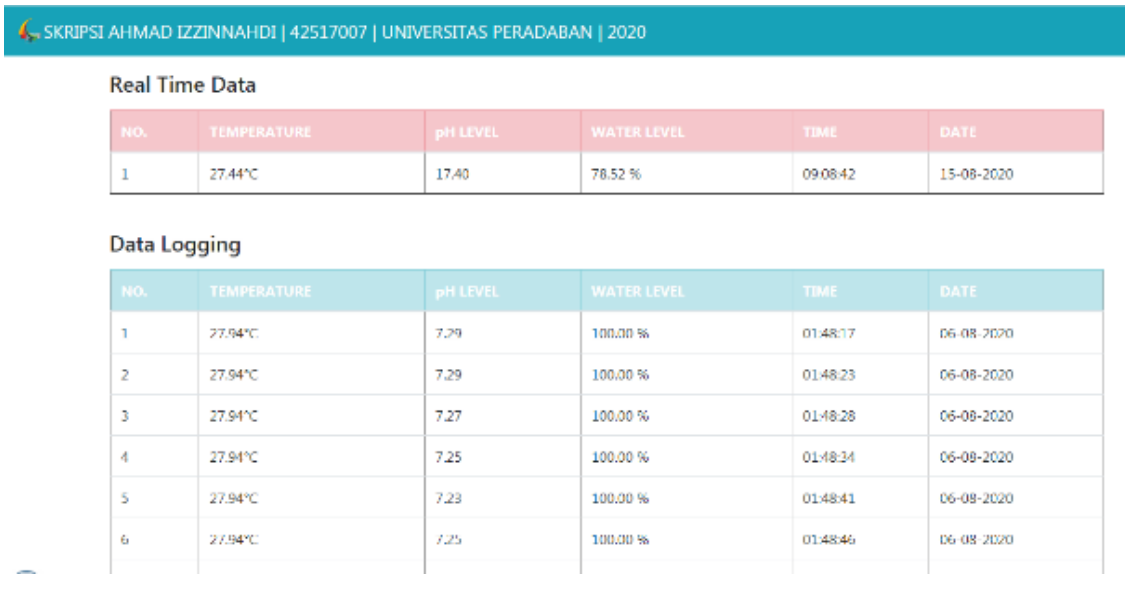

Gambar 6 Interface Website

\section{E. Analisa Keberhasilan}

Pada Tabel 2, indikator keberhasilan dalam pembuatan alat ini adalah semua sensor dapat terbaca nilainya dan data hasil pembacaan dapat ditampilkan di dalam website menggunakan metode internet of things. Alat yang dibuat terdapat kelebihan dibandingkan penelitian sebelumnya yang sudah dijelaskan didalam peneltian terkait, diantaranya alat yang dibuat menggunakan mikrokontroller terbaru yaitu NodeMCU ESP8266. Pada saat pembuatan alat menemukan kelemahan pada sensor yang digunakan, yaitu sensor pH E-201C DfRobot. Sensor tersebut jika digunakan secara kontinyu nilai terbaca nya selalu berubah dan harus di kalibrasi secara berkala, oleh karena itu sensor tidak direkomendasikan untuk digunakan secara kontinyu.

\section{Tabel 2 Analisa Keberhasilan}

\begin{tabular}{|c|c|c|c|}
\hline No. & Deskripsi Keberhasilan & Ya & Tidak \\
\hline 1 & $\begin{array}{c}\text { Dapat terbacanya nilai dari sensor } \mathrm{pH}, \\
\text { suhu dan ultrasonic menggunakan } \\
\text { NodeMCU ESP8266 }\end{array}$ & $\sqrt{ }$ & \\
\hline 2 & $\begin{array}{c}\text { Dapat menampilkan nilai hasil pembacaan } \\
\text { sensor } \mathrm{pH}, \begin{array}{c}\text { suhu, dan level ketinggian } \\
\text { kondisi air }\end{array}\end{array}$ & $\sqrt{ }$ & \\
\hline
\end{tabular}




\section{KESIMPULAN}

Berdasarkan perancangan dan pengujian Sistem Pemantauan Kondisi Air Hidroponik Berbasis Internet Of Things Menggunakan NodeMCU ESP8266 dapat disimpulkan bahwa hasil pengujian sensor ultrasonik dengan objek cair dengan batas minimal pengukuran yaitu dengan jarak $2 \mathrm{~cm}$ dan semakin jauh jarak sensor dengan objek, tingkat selisih makin tinggi. Pada hasil pembacaan antara sensor suhu DS18B20 dan termoter merkuri memiliki selisih yang tidak terlalu signifikan dikarenakan pembacaan sensor suhu mempunyai waktu respon \pm 1 menit untuk mendapatkan hasil yang sesuai. Pengujian pada $\mathrm{pH} 7$ dan $\mathrm{pH} 4$ yang di bandingkan antara pembacan dari sensor $\mathrm{pH}$ E-201 C dan ph meter digital terdapat selisih tidak terlalu siginifikan yaitu kisaran \pm 0.5 dan waktu respon pembacaan data dari sensor $\mathrm{pH}$ E $201 \mathrm{C}$ ini $\leq 1$ menit sesuai dengan spesifakasi dari sensor tersebut. Telah berhasil dibuat sistem Pemantauan Kondisi Air Hidroponik Berbasis Internet Of Things Menggunakan NodeMCU ESP8266.

\section{DAFTAR Pustaka}

[1] S. L. H. Siregar and M. Rivai, "Monitoring dan Kontrol Sistem Penyemprotan Air Untuk Budidaya Aeroponik Menggunakan NodeMCU ESP8266,” J. Tek. ITS, vol. 7, no. 2, pp. A380-A385, 2019.

[2] I. S. Roidah, "PEMANFAATAN LAHAN DENGAN MENGGUNAKAN SISTEM HIDROPONIK," vol. 1, no. 2, pp. 43-50, 2014.

[3] S. Swastika, A. Yulfida, and Y. Sumitro, Buku Petunjuk Teknis Budidaya Sayuran Hidroponik, 1st ed. Pekanbaru-Riau: Balai Pengkajian Teknologi Pertanian (BPTP) Balitbangtan Riau, Badan Penelitian dan Pengembangan Pertanian, Kementerian Pertanian, 2017 .

[4] D. Komaludin, "Penerapan Teknologi Internet of Thing (IoT) pada Bisnis Budidaya Tanaman Hidroponik sebagai Langkah Efisiensi Biaya Perawatan,” Festiv. Ris. Ilm. Manaj. Akunt., vol. 1, no. I S S N 261 4-6 68 1, pp. 682-690, 2018.

[5] N. H. L. Dewi, M. F. Rohmah, and S. Zahara, "Prototype smart home dengan modul nodemcu esp8266 berbasis internet of things (iot)," Tek. Inform. Univ. Islam Majapahit, pp. 1-9, 2018.

[6] Siswanto, T. Nurhadian, and M. Junaedi, "PROTOTYPE SMART HOME DENGAN KONSEP IOT ( INTERNET OF THING ) BERBASIS NODEMCU DAN,” J. SIMIKA, vol. 3, no. 1, pp. 85-93, 2020.

[7] D. Komaludin, "PROTOTYPE MONITORING SUHU TANAMAN HIDROPONIK TEKNOLOGI IOT ( INTERNET OF THING ) Abstrak," J. TrendTech, vol. 3, no. 1, pp. 45-51, 2018.

[8] P. W. Ciptadi and R. H. Hardyanto, "Penerapan Teknologi IoT pada Tanaman Hidroponik menggunakan Arduino dan Blynk Android," J. Din. Inform., vol. 7, no. 2, pp. 29-40, 2018.

[9] B. Haryanto, N. Ismail, and E. J. Pristianto, "Sistem Monitoring Suhu dan Kelembapan Secara Nirkabel pada Budidaya Tanaman Hidroponik," J. Teknol. Rekayasa, vol. 3, no. 1, p. 47, 2018

[10] Y. Efendi, "INTERNET OF THINGS ( IOT ) SISTEM PENGENDALIAN LAMPU,” J. Ilm. Ilmu Komput., vol. 4, no. 1, pp. 1926, 2018.

[11] H. Mas'ud, "Sistem hidroponik dengan nutrisi dan media tanam berbeda terhadap pertumbuhan dan hasil selada," Media Litbang Sulteng 2, vol. 2, no. 2, pp. 131-136, 2009.

[12] R. Rosliani and N. Sumarni, Budidaya Tanaman Sayuran dengan Sistem Hidroponik, no. 27. 2005.

[13] M. Gregoryan, J. Andrjarwirawan, and R. Lim, "Sistem Kontrol dan Monitoring Ph Air serta Kepekatan Nutrisi pada Budidaya Hidroponik Jenis Sayur dengan Teknik Deep Flow Techcnique," INFRA, vol. 7, pp. 1-6, 2019.

[14] E. E. Barus, R. K. Pingak, and A. C. Louk, "OTOMATISASI SISTEM KONTROL pH DAN INFORMASI SUHU PADA AKUARIUM MENGGUNAKAN ARDUINO UNO DAN RASPBERRY PI 3,” J. Fis. Fis. Sains dan Apl., vol. 3, no. 2, pp. 117125,2018

[15] E. Nurazizah, M. Ramdhani, and A. Rizal, "RANCANG BANGUN TERMOMETER DIGITAL BERBASIS SENSOR DS18B20 UNTUK PENYANDANG TUNANETRA,” e-Proceeding Eng., vol. 4, no. 3, pp. 3294-3301, 2017.

[16] A. Amin, "MONITORING WATER LEVEL CONTROL BERBASIS ARDUINO UNO MENGGUNAKAN LCD LM016L," EEICT, vol. 1, no. 1, pp. 41-52, 2018.

[17] A. Junaidi, "Studi Perbandingan Performansi Antar Mongodb Dan Mysq1 Menggunakan Php Dalam Lingkungan Big Data," Pros. Annu. Res. Semin. 2016, vol. 2, no. 1, pp. 460-465, 2016. 